\title{
USO Y APROVECHAMIENTO DE LAS NUEVAS TECNOLOGÍAS EN LA CONSERVACIÓN DEL PATRIMONIO EDIFICADO. RESEÑA DE CASOS EMBLEMÁTICOS EN PER Ú(*)
}

\author{
USE AND EXPLOITATION OF NEW TECHNOLOGIES IN THE CONSERVATION OF BUILT HERITAGE. \\ REVIEW OF EMBLEMATIC CASES IN PERÚ
}

\author{
SILVIA QUINTO FERNÁNDEZ ${ }^{(\star)}$ \\ Fecha de recepción: 29 de abril de 2016 \\ Fecha de aprobación: 22 de mayo de 2016
}

\begin{abstract}
RESUMEN
El uso y aprovechamiento de las nuevas tecnologías en el conocimiento, conservación e intervención del patrimonio edificado en el Perú está atravesando una fase de experimentación y aplicación en proyectos específicos.

Esta reseña busca resaltar experiencias concretas realizadas en el territorio peruano por parte de instituciones internacionales, nacionales y privadas, orientadas a la conservación del vasto legado patrimonial, revisando el uso de diferentes recursos tecnológicos para su digitalización, recreación o representación virtual. Se trata de ejemplos que van emergiendo en el quehacer nacional y que deben considerarse en la formación especializada del profesional en patrimonio edificado, enfatizando su carácter multidisciplinario.
\end{abstract}

\section{PALABRAS CLAVE}

Nuevas tecnologías, patrimonio construido del Perú, digital

\section{ABSTRACT}

The use and development of new technologies in knowledge, conservation and intervention of the built heritage in Peru is passing through a phase of experimentation and application on specific projects.

This review attempts to highlight practical experiences developed in Peru by international, national and private institutes in the conservation of heritage legacy, analyzing the use of different technological sources for digitalization, recreation and virtual representation.

The examples are emerging from national affairs and are to be considered in the specialized professional training in built heritage, emphasizing its multidisciplinary nature.

\section{KEYWORDS}

New technologies, built heritage of Perú, digital

(*) La presente publicación es producto de una de las líneas de investigación personal de auspicio propio y constituye expresión del esfuerzo sostenido desde la última década -pero con especial énfasis desde 2002- que viene llevando a cabo la autora del presente artículo por dar a conocer y analizar la aplicación de las nuevas tecnologías disponibles para la conservación del patrimonio edificado en el medio peruano.

(**) Profesional titulada en Arquitectura en la Universidad Ricardo Palma, con estudios de Maestría en Conservación del Patrimonio Edificado en la Universidad Nacional de Ingeniería; con amplia experiencia en el desarrollo de proyectos, consultoría y docencia en el área de diseño; une a su labor, la investigación histórica y su permanente actualización en el campo arquitectónico y patrimonial. Contacto: silviaquintof@gmail.com 
Patrimonio Edificado.- Es la "memoria", la "construcción social", el "legado" (Hayakawa, 2010), que nos permite, en una mirada hacia atrás, conocer o reconocernos, valorando su presencia aún física, al tener la oportunidad de recorrerla y'vivirla' con todos nuestros sentidos, de modo que al ir descubriéndola dilucidemos todo lo que encierra, y lo que significan el tránsito y los logros alcanzados por las sociedades de tiempos pasados en relación a nuestro desarrollo.

Tecnología.- Hoy, en la era de la información, 'las nuevas tecnologías', en permanente cambio y evolución, son el potencial hacia el mañana que inundan el quehacer profesional diario; sus usos y posibilidades de aplicación se expanden constantemente, lo que genera nuevas formas de interacción en la sociedad. Nunca como hoy la avalancha de información y conocimientos a nuestra disposición exige inmediatez, validez y actualización constante en todas las actividades que desarrollamos.

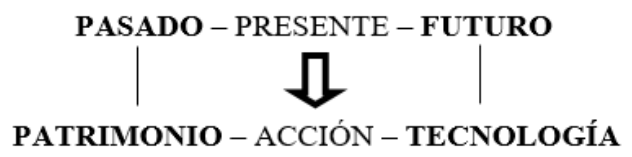

\section{Antecedentes}

El avance vertiginoso de la tecnología y la sociedad digital impacta en todas las actividades y ámbitos del ser humano. Puede afirmarse que su uso y aprovechamiento en el campo de la conservación del patrimonio edificado inició en 1980, con las primeras reconstrucciones virtuales que expresaban el estado de edificios históricos en ese momento.

Recién en la década de 1990 "se exponía la posibilidad de usar los modelos virtuales como un sistema de interpretación de los restos arqueológicos de los monumentos históricos" (Gómez \& Quirosa, 2009).

De 2001 a 2016, la socialización del Internet y la consecuente aparición de comunidades virtuales ha permitido otras perspectivas de encuentro, de relaciones e intercambios intelectuales. La difusión en el quehacer especializado patrimonial va incorporando estas nuevas herramientas.

Este desarrollo tecnológico lleva a la UNESCO, en 2003, a la incorporación de la definición del 'digital heritage' (patrimonio digital), que consiste en "...recursos únicos que son fruto del saber o la expresión de los seres humanos. Comprende recursos de carácter cultural, educativo, científico o administrativo, e información técnica, jurídica, médica y de otras clases, que se generan directamente en formato digital o se convierten a éste a partir de material analógico ya existente" (Greytsova, 2015). Se elabora así, la Carta sobre la Preservación del Patrimonio Digital con la siguiente finalidad:

- Proteger el patrimonio digital, utilizando para ello un marco jurídico y técnico para salvaguarda de la autenticidad

- Preservar el patrimonio cultural, poniéndolo a disposición de cualquier persona, independientemente de la nación, región o comunidad a la que pertenezca, de su cultura y de su estatus social

En 2008, el Consejo Internacional de Monumentos y Sitios (ICOMOS), ratificó la Carta de Ename, en la cual se establecen siete principios fundamentales para la interpretación y presentación de sitios de patrimonio cultural, donde se explicita en el "Principio 2: Fuentes de Información", artículo 4, lo siguiente:

Las reconstrucciones visuales, ya sean realizadas por artistas, arquitectos o diseñadas mediante ordenador, se deben basar en un análisis detallado y sistemático de los datos medioambientales, arqueológicos, arquitectónicos e históricos, incluyendo el estudio de las fuentes escritas, orales e iconográficas, así como de la fotografía. 
Las fuentes de información en las que se basen tales reproducciones deben documentarse de forma clara y es preciso facilitar reconstrucciones alternativas, cuando esto sea posible, basadas en las mismas evidencias para su comparación.

Durante los últimos años, a nivel internacional, se ha propiciado la elaboración y ejecución de proyectos encaminados a investigar, preservar, interpretar y presentar el patrimonio edificado mediante la utilización de la visualización asistida por ordenador, que ha demostrado su extraordinario potencial. Su manejo y análisis brindan nuevas oportunidades en la evaluación previa de intervenciones, y su impacto en el patrimonio edificado.

El Comité Internacional para la Documentación del Patrimonio Cultural (CIPA), en colaboración con la Sociedad Internacional de Fotogrametría y Teledetección (ISPRS), conocedores de este potencial y el incremento de su uso, elaboraron la Carta de Londres (2006-2009): "Para la Visualización Computarizada del Patrimonio Cultural", que expresa entre sus objetivos los siguientes:

- Proponer una serie de principios para el uso de los métodos y de los resultados de la visualización computarizada en el campo de la investigación y divulgación del patrimonio cultural

- Promover el rigor intelectual y técnico en las visualizaciones digitales del patrimonio

En el Principio 1.1 recomienda que "Cada comunidad de expertos, deberá desarrollar las directrices de implementación de la Carta de Londres de manera coherente con sus propias pretensiones, objetivos y métodos" (Carta de Londres, 2008, p. 4). Ya que se trata de principios de aplicación para el trabajo patrimonio cultural en general, la Sociedad Española de Arqueología Virtual, conjuntamente con la Red Internacional de Arqueología Virtual, crean el Fórum Internacional de Arqueología Virtual, donde logran desarrollar, de 2008 a 2011, tras sucesivas actualizaciones, Los Principios de Sevilla, conjunto de recomendaciones aplicables al campo de la arqueología virtual (de aplicación también a lo arquitectónico). Ambos documentos normativos internacionales se han convertido en referentes para el desarrollo de trabajos de visualización digital.

La importancia de la aplicación digital a nivel patrimonial sigue su curso con la realización de diversos eventos académicos internacionales:

- Digital Heritage, promovido por ICOMOS a partir del año 2013, un congreso internacional bianual sobre la aplicación de nuevas tecnologías en conservación, restauración, gestión, documentación, y puesta en valor del patrimonio histórico y cultural

- ARQUEOLÓGICA 2.0, Congreso de Arqueología e Informática Gráfica, Patrimonio Cultural e Innovación, que promueve su octava edición (2016) con el lema "Documentación 3D: avanzada, modelado y reconstrucción de objetos patrimoniales, monumentos y sitios"

A nivel latinoamericano, el Instituto Nacional de Antropología e Historia (INAH) de México impulsa los siguientes eventos:

- El Congreso Internacional del Patrimonio Cultural y las Nuevas Tecnologías (anualmente, a partir de 2014), que propugna el pleno uso de las herramientas tecnológicas disponibles para conocer, conservar y difundir el patrimonio cultural mexicano

- La Red Temática en Tecnologías Digitales para la Difusión del Patrimonio Cultural (desde junio de 2015), promueve como grupo de trabajo interdisciplinario y multisectorial la generación de conocimiento, y el ejercicio de buenas prácticas en la aplicación de las tecnologías digitales para la difusión del patrimonio cultural 


\section{Las nuevas tecnologías en relación al patrimonio edificado}

\section{La Fotogrametría: el precedente analógico}

El significado etimológico de 'fotogrametría', término derivado de 'fotograma'y 'metría', y estas a su vez de las raíces griegas 'phos', 'photós' = luz; 'gramma' = trazo, dibujo; 'metrón' = medir, medida, sería: 'medir sobre fotos'. El arquitecto Albretch Meydenbauer acuñó el término, y es el responsable del desarrollo de la fotogrametría arquitectónica como método óptico de relevamiento de edificios, basado en la combinación de métodos topográficos e imágenes fotográficas, que obtiene planos y documentación de gran exactitud para utilizarlos en la restauración o reconstrucción del patrimonio afectado por el tiempo.

Desde 1858, diseñó cámaras, lentes y métodos de toma fotográfica, desarrollando la técnica de dimensionamiento y posicionamiento de objetos en el espacio. A través de las medidas obtenidas por la intersección de dos o más fotografías, construía la información bidimensional y geométrica del objeto. A partir de la zona común a aquellas (zona de solape) se podía tener visión estereoscópica o información tridimensional.

Hasta 1920 generó 20,000 registros fotogramétricos de unas 2,600 construcciones ubicadas dentro y fuera de Alemania, documentación que sirvió para la reconstrucción de la antigua Berlín después de la Segunda Guerra Mundial.

\section{Hoy: las tecnologías digitales}

El uso, manejo y dominio de las herramientas digitales ha dado lugar a nuevas formas de lograr la representación, conocimiento, evaluación, conservación y difusión del patrimonio edificado. Respecto a ello, se pueden diferenciar tres grandes categorías o grupos dentro del patrimonio digital (Parry, 2010):

- Patrimonio cultural arqueológico y monumental digitalizado mediante el uso de diferentes técnicas

- Recreaciones virtuales del patrimonio perdido que ha sido reconstruido digitalmente - Recursos creados para difundir el patrimonio cultural y sus valores a través de diversos soportes estáticos, interactivos, portátiles, online, como redes sociales, blogs, etc.

Por otro lado, también se pueden diferenciar dos grandes grupos de tecnologías digitales aplicables a la prospección histórico-patrimonial:

- Tecnologías digitales de elaboración de imágenes

- Tecnologías digitales de control preventivo

\section{Tecnologías digitales de imagen}

A continuación se describen las técnicas de mayor uso y aplicación en el ámbito patrimonial:

\section{- Representaciones virtuales 2D y 3D}

Desarrollo gráfico asistido por computador para la elaboración de planos de patrimonio edificado existente: planta, cortes, elevaciones, patologías, deterioros e intervenciones a realizar. Se dispone del modelado 3D, que permite la reproducción de objetos tridimensionales por computadora haciendo uso de programas como AutoCAD, Autodesk 3DMax, CATIA, entre otros.

\section{- Sistemas BIM (Building Information Modeling)}

Software de diseño 3D que permiten un entorno de trabajo colaborativo, gracias a la posibilidad de realizar cambios automáticos en tiempo real.

Programas BIM como el ArchiCAD o el Revit, usados para proyectos arquitectónicos en general, cuyo uso se incorpora progresivamente en la representación gráfica patrimonial. 


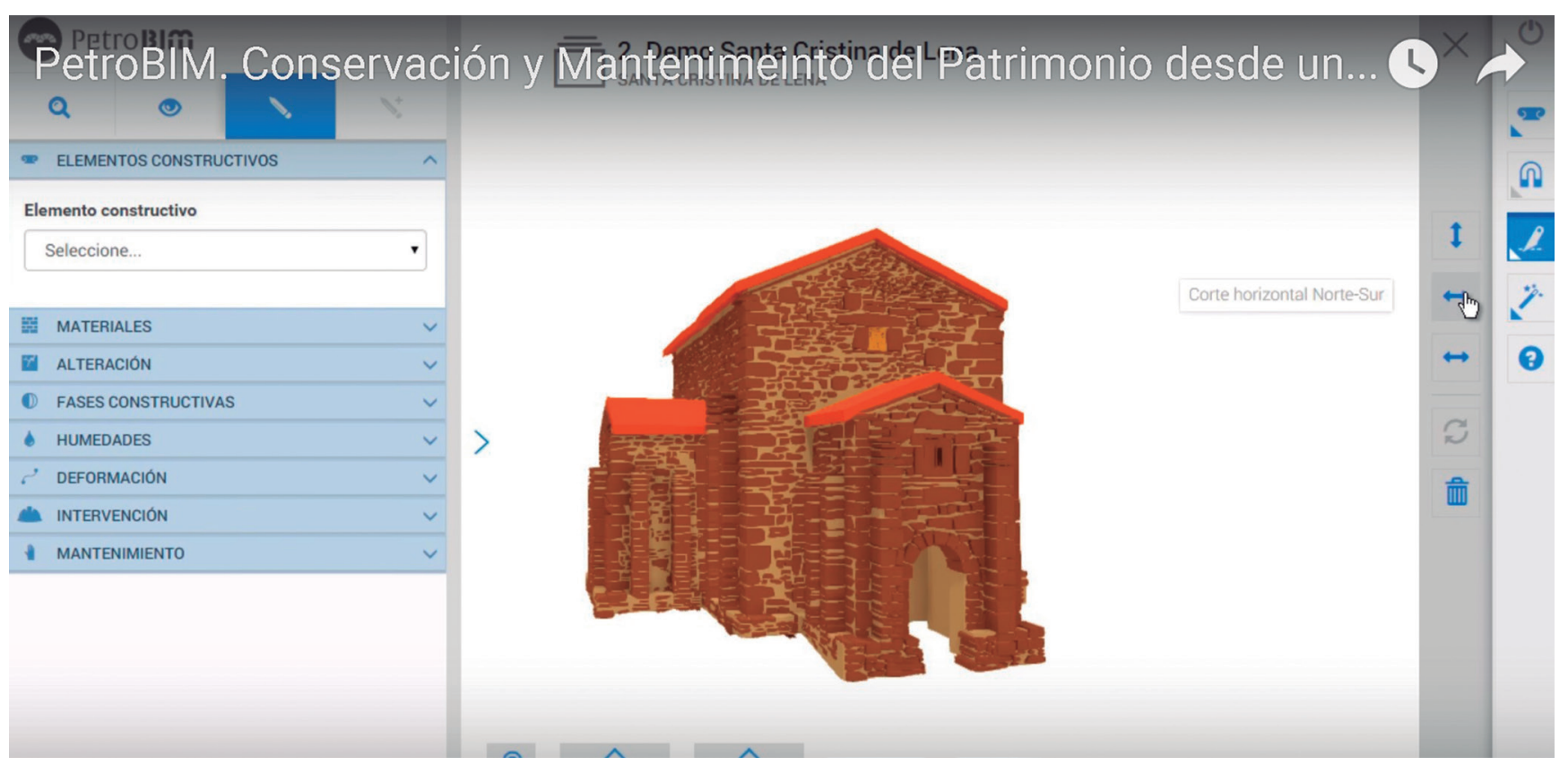

Cabe resaltar, como uno de los últimos avances tecnológicos en software específicos para el trabajo patrimonial, PetroBIM, herramienta que integra en tiempo real toda la información de un bien cultural. Dedicado específicamente a proyectos de restauración y conservación, permite obtener un modelo-maqueta virtual en el que es posible navegar, desplazarse, e interactuar desde la 'nube', reuniendo el conocimiento y experiencia de todo el equipo multidisciplinario a cargo de su intervención (ver Figura 1).

\section{- GPS (Sistema de Posicionamiento Global)}

Sistema de navegación por satélite que a través de triangulación determina la posición y dirección de cualquier objeto para la elaboración de planos topográficos, o de sitios arqueológicos. El GPS Diferencial o DGPS es un sistema que permite mayor exactitud en la determinación de la posición de los objetos.

- SIG ó GIS (Sistema de Información Geográfica)

Permite integrar y analizar data geográfica para su visualización en mapas.

- Motores de juego de Blender (Blender Game Engine)

Software libre de modelado, animación y creación 3D. Su uso y aplicación en la creación de videojuegos se extiende a la construcción de escenarios virtuales que permiten interactuar con objetos, monumentos y yacimientos arqueológicos, y generar el desplazamiento, visualizadores interactivos o recorridos dentro del patrimonio (ver Figura 2).

\section{- Escaneo láser}

El conocimiento y aplicación de técnicas basadas en láser para la labor en arqueología, historia del arte y patrimonio edificado se aplicó inicialmente en la limpieza de bienes muebles e inmuebles.

Ben Kacyra, ingeniero de origen iraquí, inventó el primer escáner láser 3D portátil en la década de 1990, un haz de luz que va y viene del objeto al reflejarse contra una superficie y escanea los objetos, calculando la distancia y posición a partir de la diferencia
Figura 1. Software especializado para proyectos de patrimonio edificado Fuente: Programa PetroBIM, https:// www.youtube.com/watch? $v=$ j7wttzxynAg, 2015. 
Figura 2. Nuevas tecnologías de aplicación en el patrimonio

Fuente: Elaboración y edición Silvia Quinto sobre la base de http://cnnespanol.cnn.com/2015/06/24/ inventan-un-laser-para-preservar-losmonumentos-historicos-de-la-humanidad/\#more-181272; https://www. facebook.com/Engineering-and-Heritage-676639409135266/, 2015.

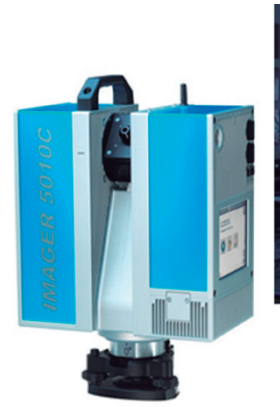

Escáner láser agrimensura y arquitectura 3D

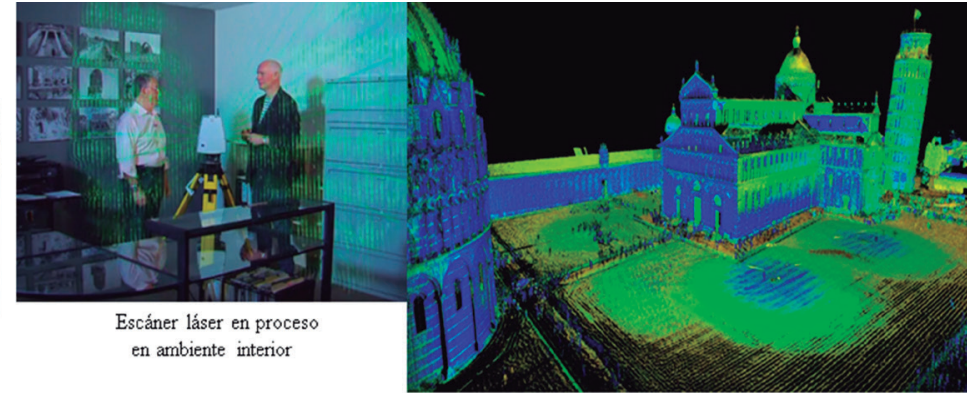

Imagen resultante de escaneado de espacio exterior
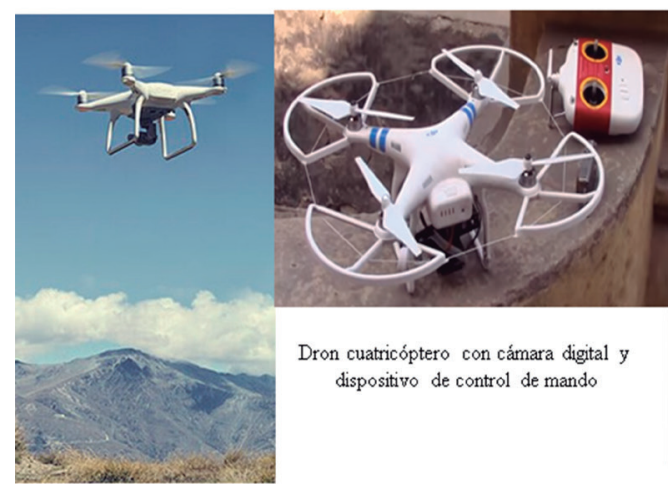

Dron cuatricóptero con cámara digital y dispositivo de control de mando

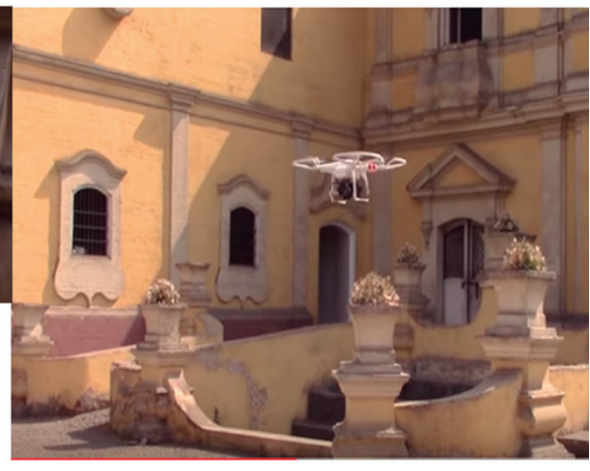

de tiempo entre el pulso de salida y el pulso de llegada. Recolecta hasta 1 millón de puntos por segundo. Luego se recogen y procesan los datos del escáner láser 3D o escáner láser de tiempo de vuelo (en forma de archivos de puntos) con un programa que permite el manejo de la 'nube de puntos', situando la visualización en planta, elevación, o realizando cortes y exportándose a diferentes programas.

Su capacidad de realizar análisis en tiempo real, sobre cualquier tipo de material, de forma no destructiva, conjuntamente con los avances de la miniaturización, brinda la posibilidad de tener cada vez mayores opciones de equipos portátiles de alta gama, y mayores posibilidades de uso y aplicación.

A raíz de la destrucción de los Budas de Afganistán, en 2001, Ben Kacyra fundó Cyark, con la misión de conservar la memoria humana colectiva. Trabaja en escanear, a partir del año 2003, distintas estructuras históricas para preservar versiones digitales de la arquitectura antigua del mundo.

\section{- Modelos digitales terrestres MDT}

Haciendo uso de escáner láser para la captura de puntos, cartografías digitales y software variados, como infografía 3D Blender, se logra la reconstrucción ambiental, que expresa la topografía, vegetación, geología e hidrología de un sitio patrimonial con renderizado fotorrealista.

\section{- Sistema de vuelo no tripulado}

El uso de vehículos aéreos no tripulados VANT o drones permite el registro fotográfico, mediante video o barrido laser, de sitios arqueológicos, edificaciones o centros históricos. Las capturas de imágenes hechas con un previo plan de vuelo permiten realizar lo siguiente:

- Reconstrucciones 3D a partir de fotos traslapadas (fotogrametría con drones) 


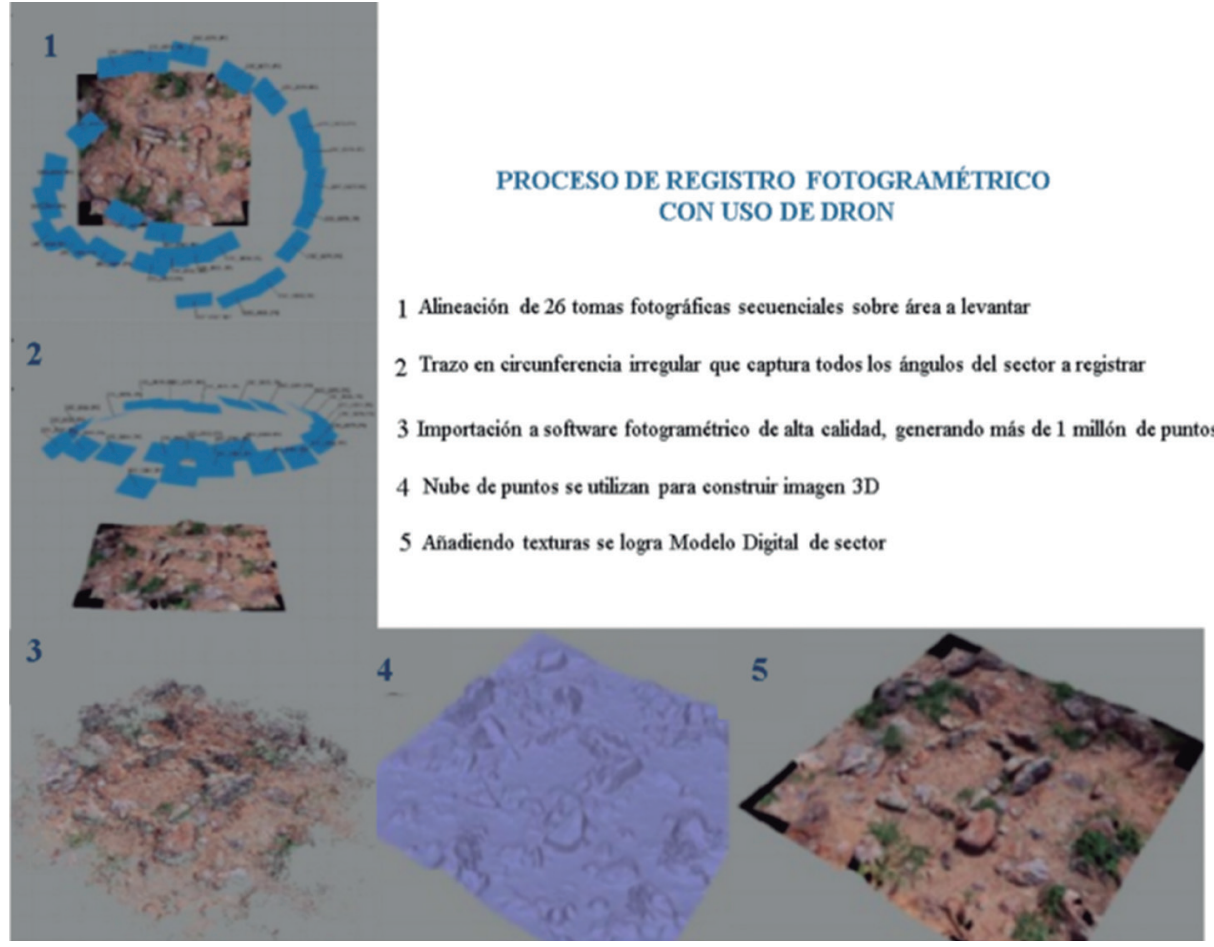

- Mapas digitales, ortofotos (fotografías aéreas planas, perpendiculares sin distorsiones, con medidas reales, y de resolución milimétrica)

- Modelos virtuales 3D georreferenciados que permiten visualizaciones en todas dimensiones y el manejo virtual en cualquier posición

Entre las ventajas del uso de drones, está la posibilidad de accesibilidad a sitios remotos o peligrosos. También pueden hacer uso de distintos tipos de cámaras de muy alta resolución, de gran alcance, de visión en condiciones de poca luz, térmicas o termográficas, gracias a lo cual permiten realizar lo siguiente:

- El diagnóstico y monitoreo estructural

- La evaluación ambiental del sitio y el entorno (ver Figura 3)

El uso y aplicación de una o más herramientas permiten la realización de la visualización del patrimonio a través de dos tipos de sistemas:

- Realidad virtual.- "Representación de escenas o imágenes de objetos producidos por un programa informático, que da la sensación de su existencia real" (Realidad virtual, 2014 , s.n.). A esta sensación se la llama fotorrealismo; no son verdaderas fotografías, sino imágenes que se aproximan bastante a la realidad; pueden en algunos casos verse a través de pantallas o impresos.

- Realidad aumentada.- Cuando se mezclan entornos reales con entornos virtuales, superponiéndose, pueden contemplarse con el uso de gafas o cascos de realidad virtual.

\section{Tecnologías digitales de control preventivo}

El avance tecnológico brinda también herramientas para el control, monitoreo, evaluación y mantenimiento preventivo del bien patrimonial:
Figura 3. Proceso de registro fotogramétrico con uso de dron Fuente: Edición Ilustración 28 Dueñas, M., 2014. 
Replica modelos en computadora, para analizar el comportamiento de materiales desde el punto de vista experimental. Permite la realización de ensayos en laboratorio (comprimirlos, cortarlos, flexionarlos); calibrados, los modelos computacionales permiten un análisis estructural avanzado para predecir el comportamiento de la estructura ante cargas como sismos, vientos, etc.

\section{- Red de sensores inalámbricos}

Registra los valores de temperatura, humedad, iluminación, presencia e incluso $\mathrm{CO}_{2^{\prime}}$ información que es remitida mediante tecnologías Machine-to-Machine (M2M), dispositivo que permite el intercambio de información entre dos máquinas remotas a través de la red de telefonía móvil e Internet.

\section{- Aplicaciones tecnológicas 'SMART'}

Tecnología inteligente que integra lo digital y el uso de Internet, lo cual permite el control de los parámetros más importantes de cualquier monumento, su gestión, monitorización eficiente, diseño de estrategias para su mantenimiento, y permite detectar en tiempo real todos los factores que pueden poner en riesgo la conservación del monumento.

\section{Las nuevas tecnologías en el patrimonio edificado del Perú}

En el Perú, el uso y aplicación de nuevas tecnologías en relación al mundo del Diseño, la Arquitectura, la Arqueología y la Ingeniería se ha dado en paralelo al avance del sector informático, inicialmente con el manejo de programas y aplicaciones que permiten hacer mucho más real la producción de los proyectos.

A partir de 1994 los sistemas CAD desarrollados por la empresa Autocad, hoy Autodesk, se tornaron en herramienta de uso cotidiano para la labor de los profesionales del sector, junto con los inicios del acceso a Internet, promovido por la Red Científica Peruana (RCP). Se instaló la primera cabina pública en el país, de acuerdo a un modelo de acceso comunitario, lo cual permitió que cualquier persona hiciera uso del Internet sin restricción alguna. Ello generó el aumento progresivo de las cabinas en tanto centros de negocios, así como del número de usuarios conectados y el desarrollo del conocimiento de las aplicaciones informáticas.

En el archivo del Organismo Supervisor de Inversión Privada en Telecomunicaciones (OSIPTEL), entidad pública encargada de regular y supervisar el mercado de servicios públicos de telecomunicaciones con respecto al servicio de Internet en el país, se indica que a diciembre de 2001, debido a la gran oferta de líneas dedicadas de acceso a Internet por parte de varios proveedores de servicios, al abaratamiento gradual de las PCs y a la demanda de la población, existían aproximadamente 1,740 cabinas públicas de acceso a Internet a nivel nacional (Organismo Superior de Inversión Privada en Telecomunicaciones, 2002, p. 3). La masificación de la tecnología de las comunicaciones, y el uso de las computadoras en instituciones académicas y posteriormente en las viviendas generó paulatinamente todo un fenómeno social y cultural.

La creciente expansión y evolución de la tecnología para desarrollar e integrarse a sistemas de realidad virtual llevó progresivamente a la interacción con prototipos virtuales en las computadoras.

De 2001 a 2016, el trabajo de virtualización patrimonial ha empleado las mismas herramientas (CAD, 3DMAX) utilizadas para el desarrollo de proyectos en general.

A partir del año 2013 se inicia la incorporación del uso de drones en entidades públicas para realizar registros y evaluaciones diversas (ver Figura 4). 
LINEA DE TIEMPO DE APLICACIÓN DE NUEVAS TECNOLOGLAS EN EL PERU
Wiracocha:

Checacupe *

Andah.-Huaro*

3 HUACA LA LUNA*

QUINTA DE PRESA

Proyectos
en Perú

Proyectos
en Perú

2 RECONSTRUCCION 3D CON DRONES

\section{NAZCA}

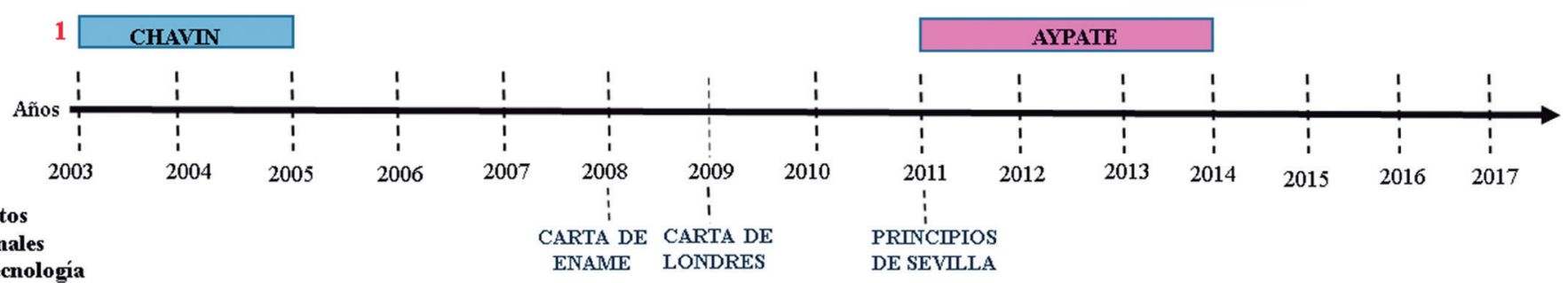

Documentos

Internacionales

Patrimonio-Tecnología

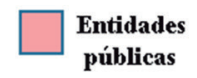

internacionales públicas

\section{Entidades públicas \\ en convenio con internacionales}

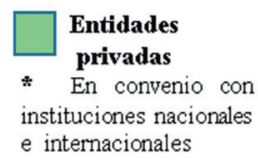

$e$ internacionales
1, 2, 3 Casos a resaltar

Fuente: Elaboración propia

\section{Reseña de casos emblemáticos}

Entre las experiencias prácticas de aplicación de nuevas tecnologías realizadas en el territorio peruano se han seleccionado tres casos, clasificados según el tipo de promotor: instituciones internacionales, públicas o privadas.

\section{Caso 01: Instituciones internacionales. Entidad: Universidad de Stanford-Uni- versidad de California, Berkeley-Fundación Kacyra: Proyecto Sitio Arqueológi- co de Chavín (2004-2005)}

Es posible determinar el inicio del empleo de aplicaciones tecnológicas en el Perú en los trabajos realizados sobre el Sitio Arqueológico de Chavín, declarado por la UNESCO el 6 de diciembre de 1985 Patrimonio Cultural de la Humanidad.

Chavín, centro ceremonial precolombino construido en piedra labrada, ubicado en las faldas orientales de la Cordillera Blanca y el Callejón de Conchucos, se desarrolló entre los años 1,500 a 300 a.C., a 3,180 m.s.n.m., en el distrito de Chavín, provincia de Huari, departamento de Áncash, Perú. Abarca una extensión de 14.79 has, y presenta las únicas galerías subterráneas que pueden ser visitadas en el Perú.

Su ubicación estratégica le permitía fungir de conexión entre la selva y la costa, el este y el oeste, el norte y el sur, posición ideal para el comercio y recolección de bienes en sus tiempos de esplendor.

En julio del año 2004 y 2005 -en dos temporadas-, el proyecto CyArk de la Fundación de la Familia Kacyra, junto con un grupo de estudiantes de la Universidad de California, Berkeley, realizó el trabajo 3D de escaneo láser, para apoyar y complementar las actividades arqueológicas de investigación realizadas en el sitio bajo la dirección de John Rick, de la Universidad de Stanford.
Figura 4. Línea de tiempo de aplicación de nuevas tecnologías en el Perú

Fuente: Elaboración y edición Silvia Quinto, 2016. 
Utilizando un escáner Leica HDS 2,500, y técnicas de escaneo láser -gama larga y estrecha-, fotografías panorámicas, fotografía a intervalos y de corto alcance de escaneado $3 \mathrm{D}$, con el objetivo de registrar tridimensionalmente todas las estructuras sobre el suelo y las galerías subterráneas, elaboraron un modelo exacto para la ejecución de un plan de conservación para el sitio.

De la entrevista a Jhon Rick publicada en la revista Desarrollo, Turismo y Cultura desde la Periferia (2006), extraemos un comentario suyo concerniente a la aplicación de nuevas tecnologías aplicadas en el sitio arqueológico:

\section{¿Cómo han realizado el mapeo interno del Templo Chavín?}

Bueno, ya que resulta dificilísimo mantener un control de espacio y dimensionalidad en espacios internos, nos hemos metido cada vez más profundamente en lo electrónico comprobando nuevos sistemas en versión Beta. Hace dos años (2004) hicimos un escaneo tridimensional y tomamos alrededor de 200 millones de mediciones en forma muy rápida. Ahora conocemos el contorno interno y externo del templo a un nivel de detalle que tienen muy pocos lugares en el mundo.

Siempre venimos documentando el sitio en esta forma, pero desde hace más o menos 6 años (Año 2000) empezamos a trabajar dándole más énfasis a la conservación. Hacemos también excavaciones con valor de investigación, pero siempre excavaciones orientadas hacia la conservación.

Chavín necesita tanta conservación que cualquier investigación tiene que tomar en cuenta esta necesidad. (Brescia, 2011) (ver Figura 5)

John Ristevski, director de Investigación y Tecnología de Cyark, indica al respecto lo siguiente:

....El escaneo láser, en combinación con otras técnicas de documentación digital y tradicional, proporcionan una manera extremadamente útil para documentar las características espaciales de estos sitios. Esta información espacial constituye no sólo un registro exacto de estos sitios en rápido deterioro, que puede ser guardado para la posteridad, sino que también proporciona un conjunto de datos de base amplia, en la que los administradores de sitios, arqueólogos y conservadores pueden monitorear sitios y llevar a cabo trabajos de restauración necesarios para garantizar su integridad física integridad. (Ristevski, 2006)

El registro digital también facilita su accesibilidad a un público más amplio a través de Internet. CyArk, una organización sin fines de lucro, asumió la construcción de un archivo y portal web, elaborando proyectos de digitalización tridimensional del patrimonio alrededor del mundo desde el año 2003, datos disponibles, y de libre acceso para los administradores de sitios, investigadores, estudiantes y público en general (ver Figura 6).

\section{Caso 02: Instituciones públicas. Entidad: Ministerio de Cultura del Perú. Proyec- to: Fotogrametría y modelación 3D con el uso de drones (2013-2016)}

Desde el año 2013 el Ministerio de Cultura, entidad del Gobierno peruano, incorporó el uso de aviones no tripulados o drones para la obtención de imágenes aéreas, y el modelado bidimensional y tridimensional de las fotografías mediante software de fotogrametría. Dispone de nueve drones para la labor de registro catastral:

- Cuatro drones octocópteros (de ocho hélices) que tienen una autonomía de vuelo de hasta $1 \mathrm{~km}$ de distancia alrededor del centro de comando y pueden permanecer en el aire hasta 12 minutos, tomando fotografías. Las fotos juntas constituyen una ortofoto u ortofotografía que combina la cobertura temporal, la uniformidad de escala y la precisión geométrica de los mapas, lo cual permite obtener una imagen cenital exacta del sitio.

- Cinco drones cuadricópteros (de cuatro hélices) que se utilizan en la elaboración de vídeos 


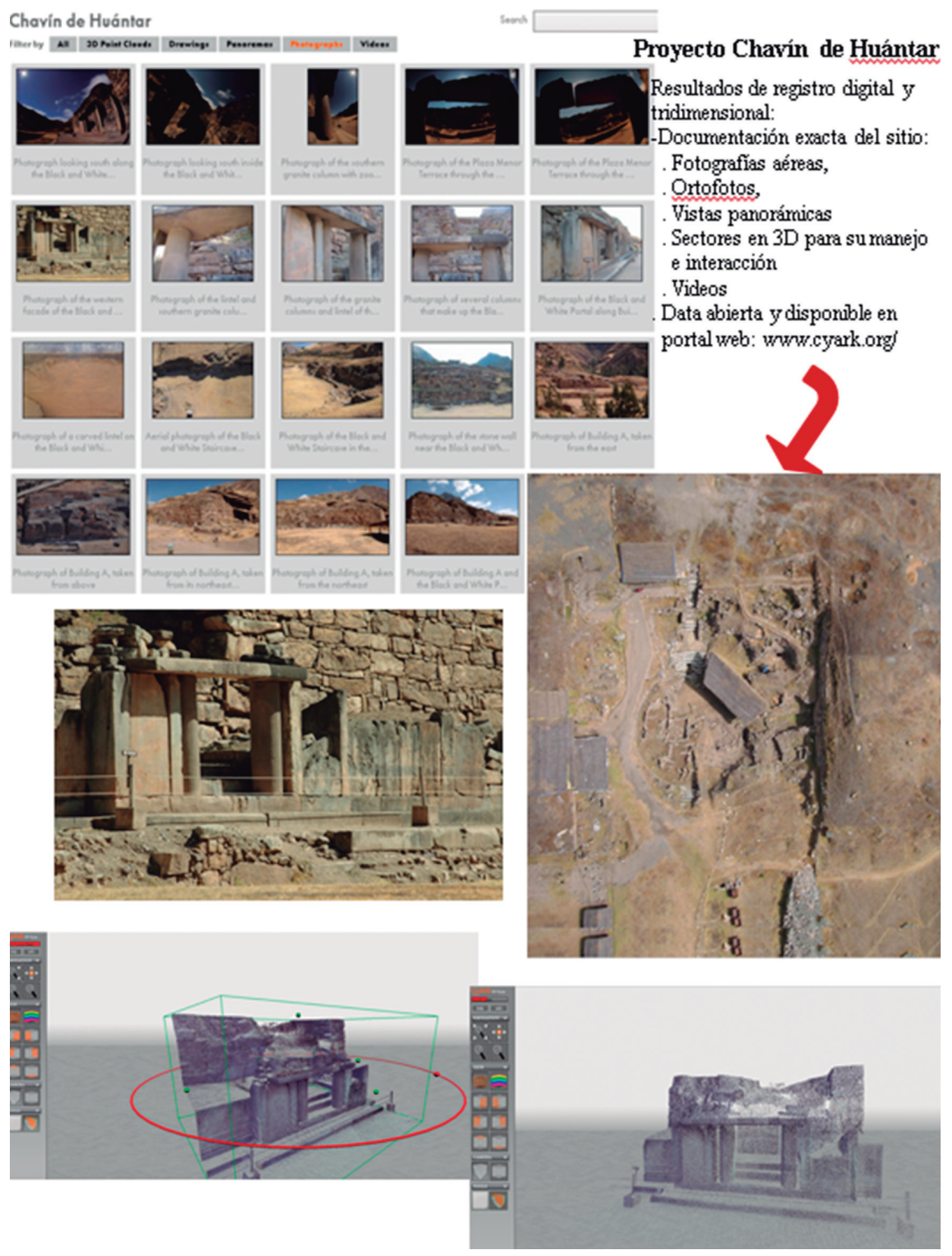

- Un GPS, dispositivo que permite georreferenciar la ubicación de los sitios registrados con margen de error de $3 \mathrm{~cm}$

Esta labor la realiza un experto en el manejo y control de los drones, mientras que otro personal controla la altura y velocidad a través de una pantalla. Los registros fotográficos y de vídeo capturados por los drones ofrecen, además, la oportunidad de redescubrir el patrimonio existente en el territorio peruano.

Al año 2016 se han registrado 700 sitios arqueológicos, de los cuales 375 se encuentran en Lima Metropolitana, de los cuales se ha obtenido planos tridimensionales que han permitido reconstruir monumentos arqueológicos como Mateo Salado, Huaycan de Pariachi, Huallamarca y Cajamarquilla, entre muchos otros.
Figura 5. Proyecto Chavín, registro digital y tridimensional

Fuente: Elaboración y edición Silvia Quinto sobre la base de http://archive.cyark.org/chavn-de-huntar-gallery; http://archive.cyark.org/chavn-dehuntar-intro, 2016. 
devenir Vol. 3, N5, ENERO - JUNIO 2016, PP. 113-132 - EstudIOS | ISSN 2312-7570

UNIVERSIDAD NACIONAL DE INGENIERÍ, LIMA

Figura 6. Resultados del registro de escaneado láser del sitio Chavín de Huántar

Fuente: Elaboración y edición Silvia Quinto sobre la base de http://archive.cyark.org/chavn-de-huntar-gallery; http://archive.cyark.org/chavn-dehuntar-intro, 2016.

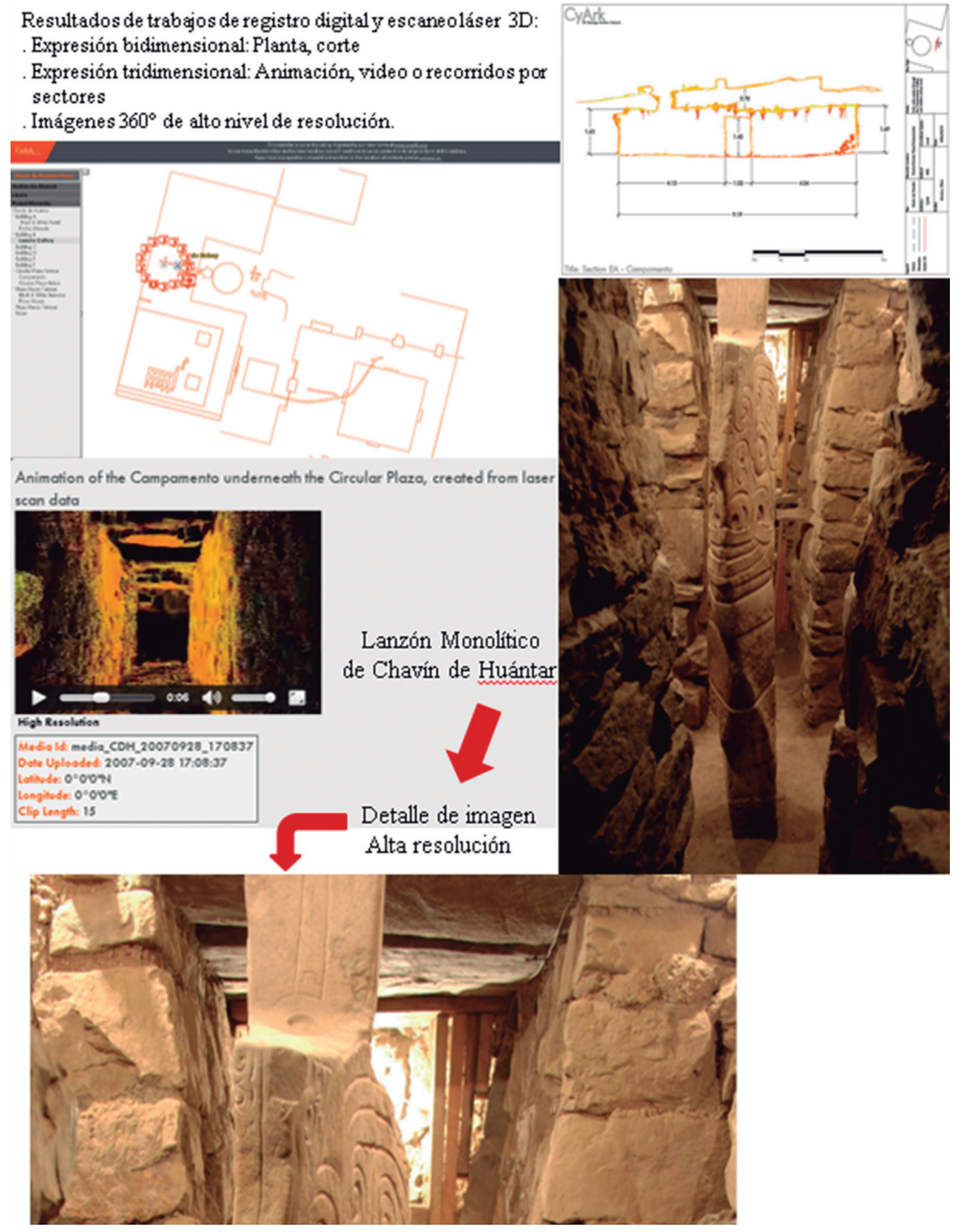

Progresivamente, la web Drones en Arqueología del Ministerio de Cultura (www.arqueologiadigital.cultura.pe), pone a disposición de investigadores y público en general las fotografías, vídeos y modelos 3D del registro ya procesado, conjuntamente con artículos que explican la labor realizada (ver Figuras 7 y 8 ).

Este Proyecto de Reconstrucción 3D y registro del patrimonio con el uso de drones ha facilitado las siguientes acciones:

- Investigación, mapeo y exploración

- Registro y actualización del estado en que se encuentra el patrimonio edificado del país

- Determinación del impacto provocado por terremotos, inundaciones, tsunamis, incendios forestales, invasiones o daños ocasionados por el ingreso ilegal a zonas consideradas patrimonio cultural 


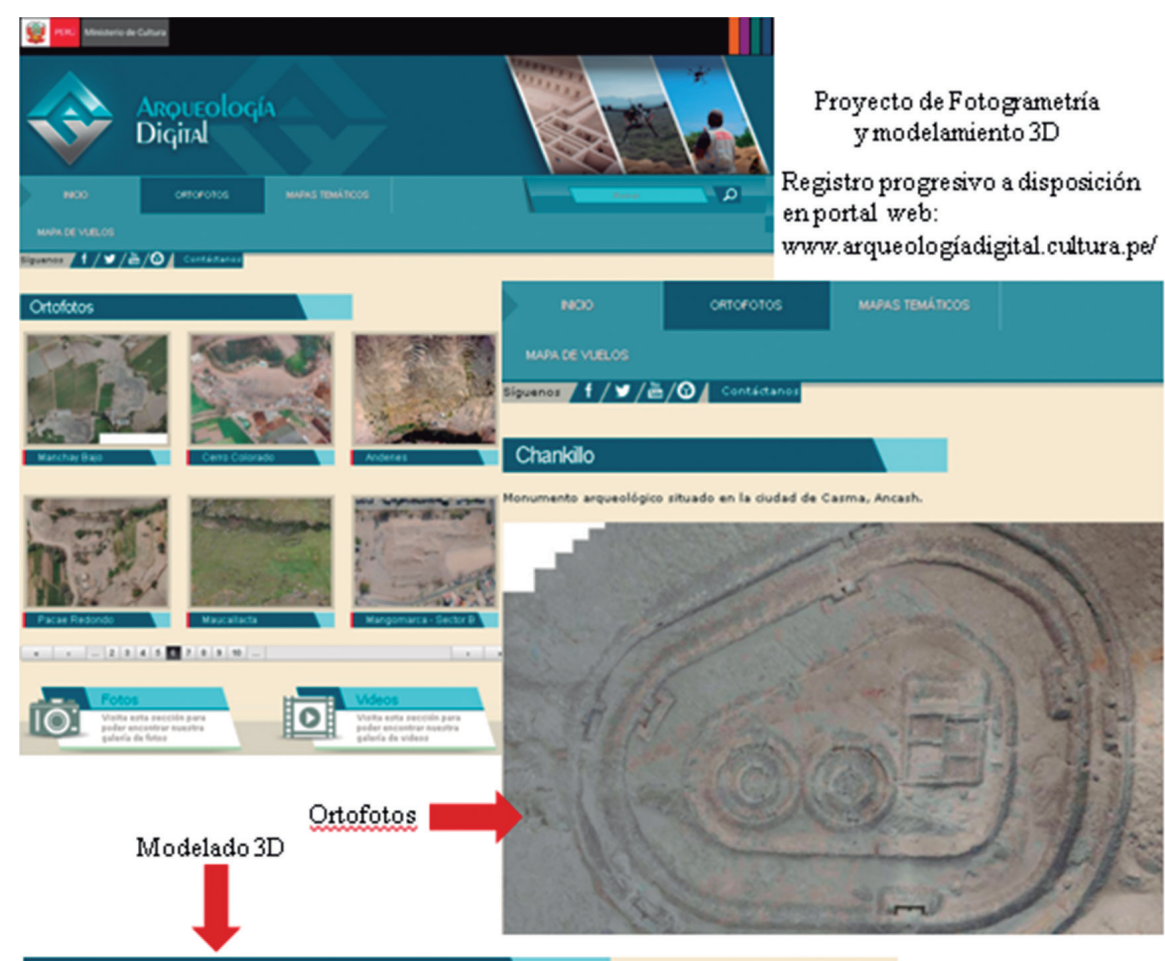

Sitio arqueológico Chankillo

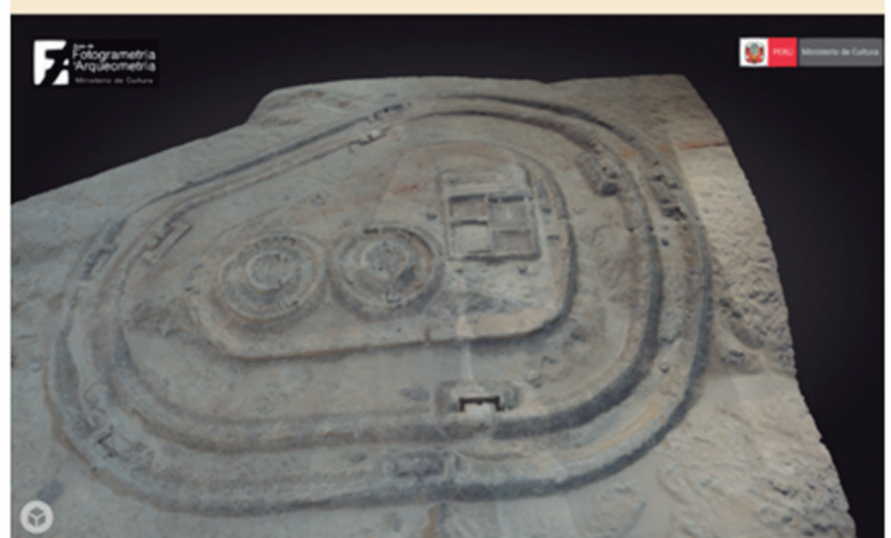

- Difusión a través de una plataforma abierta, que permite realizar paseos virtuales por los diferentes sitios arqueológicos de Lima, lo cual vuelve accesible el conocimiento sobre la riqueza patrimonial del país

- Prevención para la conservación de sitios monumentales y la reducción de riesgos de desastres. Ejemplificamos dos casos:

a Cajamarquilla, la ciudadela de barro más grande de la costa central peruana, construida entre el 600 y 730 d.C. En el proceso de registro mediante el uso de drones, se detectó vertederos de basura a los lados del camino.

a En el norte del país, al obtener información sobre el movimiento del agua en determinadas zonas de los complejos arqueológicos, se ha podido tomar medidas de prevención frente a los fenómenos climáticos.
Figura 7. Resultados del Proyecto de Fotogrametría y Modelamiento 3D

Fuente: Elaboración y edición Silvia Quinto sobre la base de www.arqueologiadigital.cultura.pe/, 2016. 
devenir Vol. 3, N5, ENERO - JUNIO 2016, PP. 113-132 - EstudIOS | ISSN 2312-7570

UNIVERSIDAD NACIONAL DE INGENIERÍ, LIMA

Figura 8. Resultados del Proyecto de Fotogrametría y Modelamiento 3D

Fuente: Elaboración y edición Silvia Quinto sobre la base de www.arqueologiadigital.cultura.pe/, 2016.

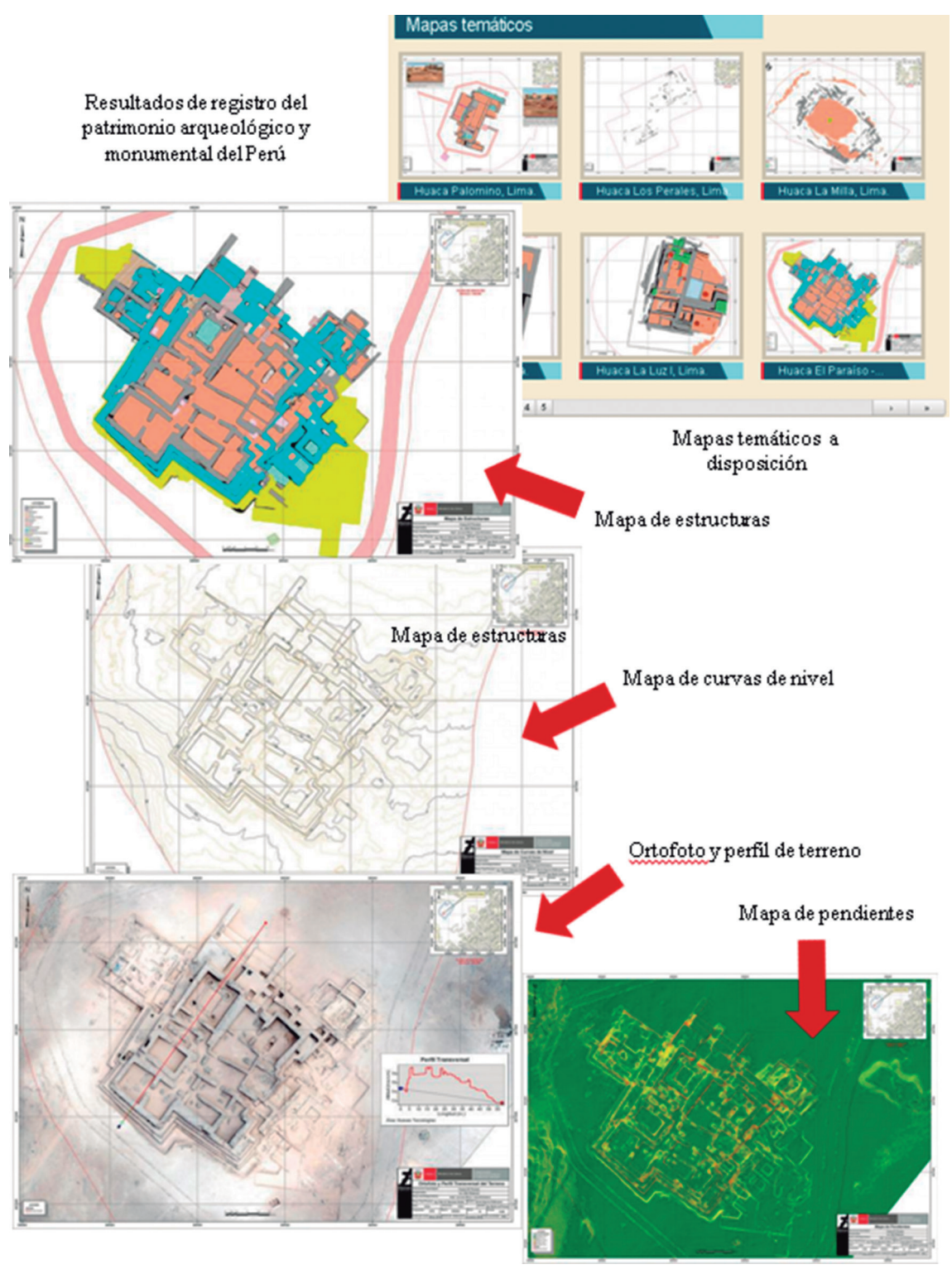

Caso 03: Instituciones privadas. Entidad: Engineering \& Heritage Research Group, del Departamento de Ingeniería de la Pontificia Universidad Católica del Perú. Proyecto: Estudio de las condiciones geotécnicas, sísmicas y de comportamiento estructural en la Huaca la Luna-Complejo Arqueológico Huacas de Moche, La Libertad-Perú (junio 2014 - junio 2015)

Engineering \& Heritage Research Group (EHRG) es un grupo de investigación multidisciplinar conformado por especialistas de Ingeniería civil, Arqueología y Procesamiento de señales. Van experimentando y desarrollando proyectos de aplicación práctica dentro de distintas áreas del territorio peruano, usando equipos de última generación para el registro, diagnóstico y conservación del patrimonio.

Cuentan con el siguiente equipamiento:

- Un sistema de geo-radar para realizar la exploración geofísica y geotécnica, y la determinación del estado estructural 
- Tres drones de última generación: un octocóptero con cámara de 24 megapíxeles y dos cuadricópteros con cámaras de 12 megapíxeles, para registrar imágenes fotogramétricas y generar modelos de las estructuras a monitorear

- Un escáner láser para llevar a abo la reconstrucción y actualización 3D de construcciones patrimoniales

- Un sistema para monitoreo de vibraciones y deformaciones

- Un sistema óptico para levantamiento geométrico

EHRG realiza ensayos del siguiente tipo:

- Geofísico: análisis multicanal de ondas superficiales

- Geotécnico: de placa de carga, muestreos, densidad de campo

- Sónico: (no destructivos), complementados con análisis numérico avanzado

- Sensorial: (previa evaluación) para registrar movimiento de la estructura y el comportamiento sísmico

- Termográfico: para determinar el estado de conservación y realizar el diagnóstico de elementos estructurales de edificaciones patrimoniales

Seguidamente se describe el proyecto representativo, en el cual también trabajaron la Universidad de Rochester (EE.UU.) y el Patronato Huacas del Valle Moche, conjuntamente con EHRG.

En la costa norte del Perú, en el departamento de La Libertad, a $8 \mathrm{~km}$ de la ciudad de Trujillo, en el Valle de Moche, se encuentra la construcción de adobe catalogada en 2013 como uno de los diez proyectos de investigación arqueológica más importantes del mundo por el Shanghai Archaeology Forum, organización que promueve la investigación, preservación y protección de los recursos arqueológicos del mundo, y de otras formas de patrimonio histórico.

La Huaca la Luna es un complejo arquitectónico compuesto por dos templos con forma de pirámide trunca, denominados Templo Viejo y Templo Nuevo. Con 12,000 $\mathrm{m}^{2}$ de murales polícromos, es un ejemplo de la tecnología constructiva que alcanzó la cultura Moche, que se desarrolló entre 400 y 600 d.C.

El Complejo Arqueológico Huacas de Moche, severamente deteriorado por la acción humana (huaqueo constante), perforado por una serie de túneles que afectan la estabilidad estructural del monumento y expuesto también a peligros naturales (sismos, fenómeno del Niño), requería de un diagnóstico estructural para su intervención, razón por la que se determinó desarrollar un proyecto interdisciplinario que integre tecnologías avanzadas. El proyecto comprendía un estudio comparativo por fotogrametría y escáner láser para la reconstrucción 3D del modelo sólido georreferenciado, y el proyecto piloto de evaluación del estado estructural actual y comportamiento sísmico de la Huaca la Luna.

Empleando el escáner láser para el levantamiento geométrico, se realizaron planos de referencia para estudiar la vulnerabilidad sísmica; se identificaron los desplazamientos relativos, y se expresó el nivel de deformaciones de los elementos estructurales y su verticalidad.

Implementado el modelo computarizado para el análisis estructural, concentrado en un sector del interior y en toda la fachada norte, se confirmaron hipótesis de problemas geotécnicos al evidenciarse muestras de daño severo en el sector superior. Se detectó en un sector del monumento un asentamiento localizado por fuera del plano de 0.4 metros. Estos resultados sirvieron de base para los trabajos de restauración y/o reforzamiento para estabilizar el sector estudiado (ver Figura 9). 


\section{Conclusiones}

La revisión de las nuevas tecnologías aplicadas a la conservación del patrimonio edificado permite conocer que en estos últimos años han tenido lugar los siguientes proyectos:

\section{A nivel internacional}

- Instituciones como Cyark han asumido el compromiso de preservar la memoria colectiva mediante un Proyecto de Registro Digital de 500 sitios patrimoniales de todo el mundo. A mayo de 2016, incluye 200 proyectos documentados en 43 países, disponibles como archivos de acceso libre al público que progresivamente se están traduciendo del inglés al español.

- La labor de instituciones como UNESCO, ICOMOS y CIPA en relación al patrimonio, junto con la aplicación de nuevas tecnologías, ha determinado la elaboración de documentos normativos internacionales como la Carta de Londres y los Principios de Sevilla, textos a considerar en los proyectos de aplicación de visualización computarizada del patrimonio cultural.

- El Profesor Dr. Víctor Manuel López-Menchero Bendicho, del Laboratorio de Arqueología y Patrimonio de la Universidad de Castilla-La Mancha, España, sintetiza y resalta los nuevos términos de ambos documentos que se incorporan al léxico y trabajo especializado patrimonial, que se resumen en la Tabla 1.

- El uso de Internet, y de proyectos disponibles a través de portales como CyArk y Google World Wonders Project, van creando bibliotecas de libre acceso del patrimonio monumental mundial antes de su posible desaparición.

- Recursos como Google Earth, Google Maps, con herramientas visuales y sistemas de navegación, como las vistas de Street View, perspectivas panorámicas, vistas virtuales de 360 grados y visualización 3D con zoom, permiten seguir descubriendo el patrimonio edificado en el mundo.

\section{A nivel nacional}

Las entidades estatales, en convenio con instituciones internacionales, y las instituciones académicas nacionales van experimentando, y aplicando progresivamente las nuevas técnicas y herramientas digitales con los siguientes propósitos:

- Registrar y documentar progresivamente el patrimonio arqueológico y monumental, de libre acceso a través de la web

- Realizar acciones para la investigación, gestión y conservación de los monumentos arqueológicos, pues hace evidente distintas situaciones:

a Ocupaciones ilegales en áreas intangibles

a Presencia de intervenciones clandestinas

a Acumulación de desperdicios o basura en sitios arqueológicos

a Determinación de deterioros o daños con mayor precisión mediante el empleo de tecnología que quita las capas superficiales y permite identificar con detalle los monumentos realizados en piedra y/o realizar nuevos descubrimientos

A nivel académico, la labor multidisciplinar va integrando a las especialidades de Ingeniería civil, Geofísica, Arquitectura, Conservación del patrimonio edificado, Geomática, y así la exploración de diversas aplicaciones a partir de la reconstrucción 3D:

- Modelos geométricos de alta precisión en su dimensionalidad 


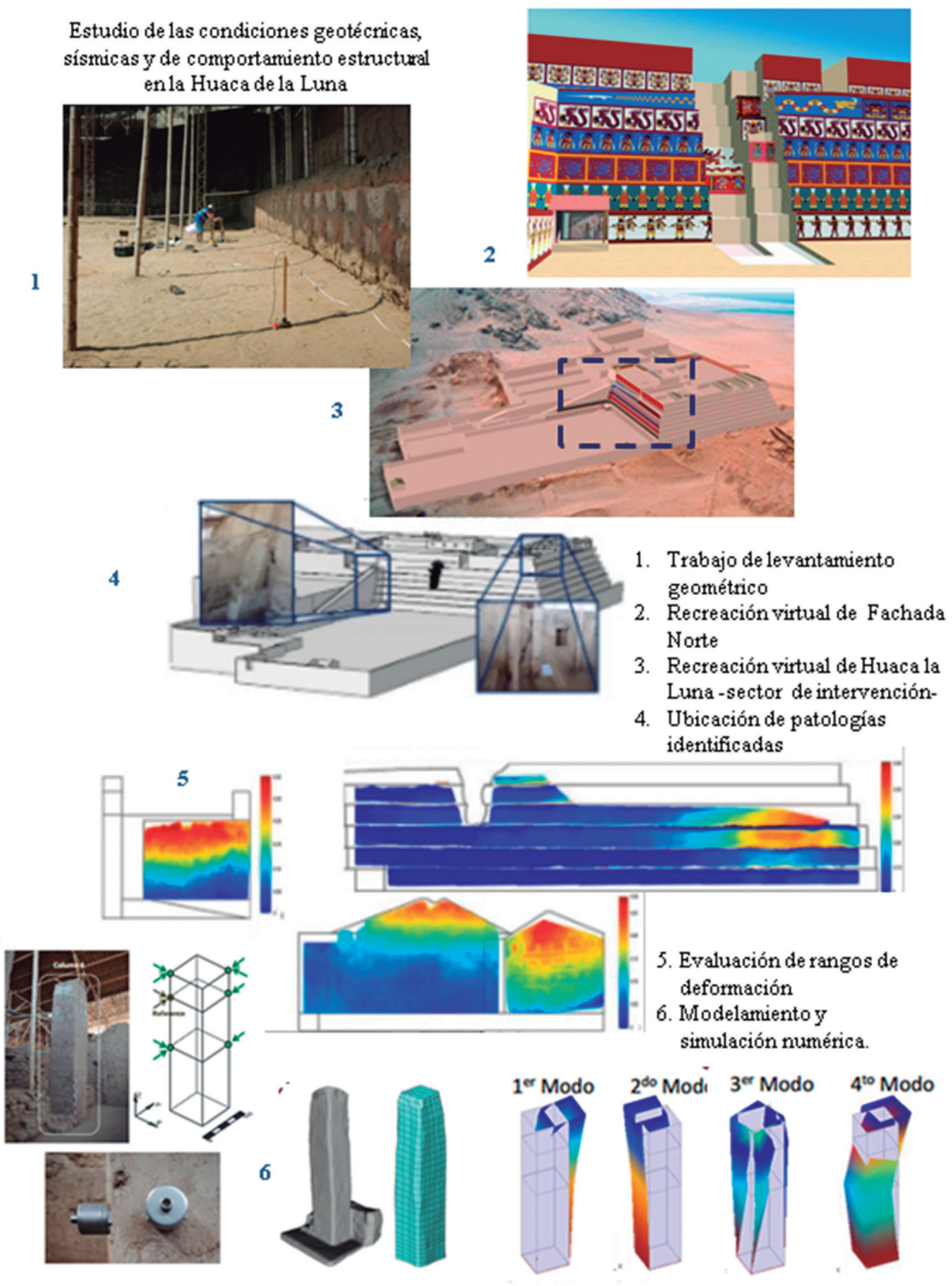

- Modelos computacionales que contienen información de los materiales, componentes y estado actual, lo cual permite realizar simulaciones en laboratorio

- Modelos predictivos para establecer su comportamiento ante fuerzas sísmicas y prever intervenciones localizadas con sustento científico

- Análisis estructural avanzado para la conservación y recuperación patrimonial

La aplicación de nuevas tecnologías abre nuevas posibilidades para monitorear, controlar y prever acciones ante la vulnerabilidad o riesgos por cambios climáticos o acciones humanas que puedan afectar la estructura o estabilidad del patrimonio arqueológico o monumental.

Por la situación de deterioro y riesgo en que se encuentra el patrimonio arqueológico y monumental, se necesita lo siguiente:

- Diseñar metodologías y procedimientos para su intervención y evaluación
Figura 9. Estudio de las condiciones geotécnicas, sísmicas y de comportamiento estructural en la Huaca la Luna Fuente: Elaboración y edición Silvia Quinto sobre la base del Coloquio de Física-Modelamiento 3D de edificios de importancia histórica usando drones y escaneo láser, recuperado de https:// educast.pucp.edu.pe/video/5637/coloquio_de_fisica modelamiento_3d_ de_e dificios_de_importancia_historica_usando_drones_y_escaneo_laser, https://www.facebook.com/Engineering-and-Heritage-676639409135266/, http://investigacion.pucp.edu.pe/grupos/shm/, 2016 
Tabla 1. Nuevos términos para el trabajo patrimonial

\begin{tabular}{cc} 
Carta de Londres & Principios de Sevilla \\
\hline Comunidad disciplinar & Arqueología virtual \\
Estrategia de sostenibilidad & Patrimonio arqueológico \\
Fuentes de investigación & Gestión integral \\
Método de visualización computarizada & Restauración virtual \\
Paradatos & Anastilosis virtual \\
Patrimonio Cultural & Reconstrucción virtual \\
Producto de la visualización computarizada & Recreación virtual \\
Relación de dependencia & \\
Transparencia intelectual & \\
Visualización computarizada &
\end{tabular}

Fuente: http://e-portfolioseav.blogspot.pe/2012/11/principios-internacionales-de-la.html, 2012.

- Modelos de actuación y trabajo multidisciplinario

La expansión de su uso se ve limitada por los costos de equipamiento, hardware y software, así como por la falta de especialización profesional en el uso y manejo de estas técnicas, sistemas y programas, que requieren de una constante actualización y trabajo multidisciplinar.

Sirva esta reseña de reflexión para lo siguiente:

- Asumir la tarea de hacer pleno uso de las herramientas tecnológicas disponibles para la conservación patrimonial

- Elaborar estrategias para vincular el conocimiento y valoración del inmenso legado arqueológico y monumental, con los recursos y aplicaciones de las que las redes e Internet permiten disponer en tiempo real

- Propiciar el análisis, difusión y aplicación de los documentos internacionales vigentes en el trabajo de conservación del patrimonio edificado

- Considerar que la reconstrucción o virtualización del patrimonio requiere el establecimiento de una terminología, protocolos y estrategias a seguir para la reintegración volumétrica y/o cromática de un bien patrimonial, que respete, entre otros, los criterios de mínima intervención, y la capacidad de discernir entre la obra original y la intervención realizada

- Integrar la 'restauración o reconstrucción virtual' como parte del trabajo profesional sustentado en una teoría, ética y estrategia de intervención que permita garantizar el carácter científico de las reconstrucciones virtuales

- Recalcar que la aplicación de nuevas tecnologías en el patrimonio edificado debe tener siempre su base en la información precisa de las fuentes, o estudios históricos y científicos. Realizar una reconstrucción o representación virtual con conocimiento y comprensión de sus antecedentes históricos permitirá validar actuaciones o intervenciones técnicas para su recuperación y conservación, y preservar su autenticidad 
- Garantizar, tal como se expresa en la Carta de Londres, que los métodos de visualización tridimensional sean aplicados con rigor académico y que cuando la investigación comprenda la representación 3D, esta dé a entender de modo preciso las diferencias entre evidencia e hipótesis

- Propiciar la creación de laboratorios abiertos (open lab, en inglés), como espacios de encuentro profesional orientados a la investigación, experimentación y desarrollo desde diferentes perspectivas, de las distintas posibilidades y aplicaciones de las nuevas tecnologías

- Valorar la relación entre tecnología y patrimonio edificado, para mejorar las condiciones del manejo, gestión y conservación del patrimonio aplicando el monitoreo del estado de la edificación patrimonial y de su uso adecuado

- Reconocer que el desarrollo tecnológico y su aplicación en edificaciones patrimoniales nos permite ir forjando una cultura universal y accesible

\section{Referencias}

Aguilar, R. (27.08.2015). Modelamiento 3D de edificios de importancia histórica usando drones y escaneo láser. En Coloquio de Física PUCP 2015: Grupo de Investigación Engineering \& Heritage. Coloquio llevado a cabo en el Departamento de Ingeniería Pontificia Universidad Católica del Perú, Lima, Perú. Recuperado de https://educast.pucp.edu.pe/video/5637/ coloquio_de_fisica_modelamiento_3d_de_edificios_de_importancia_historica_usando_ drones_y_escaneo_laser

Ayanyan, T. (2013). Chavín de Huántar. CyArk Launches website en español. Recuperado de http:// archive.cyark.org/chavn-de-huntar-intro

Boriani, M. \& Bortolotto, S. (2007). Vallorizzacione dei Beni Culturali, Milano, Italia: Centro per la Conservazione e Valorizzazione dei Beini Culturali - Politécnico de Milano.

Brescia, C. (2011). Un video ofrenda para el mundo. Recuperado de https://peregrinadanza.wordpress.com/2011/12/18/trabajos-arqueologicos-en-chavin-una-entrevista-con-john-rick/

Buill, F, Nuñez, M \& Rodríguez, J. (2008). Fotogrametría arquitectónica. Barcelona, España: Universidad Peruana de Ciencias Aplicadas.

Carta de Londres (2008). La Carta de Londres para la visualización del patrimonio cultural. Recuperado de http://www.londoncharter.org/fileadmin/templates/main/docs/london_charter_2_1_es.pdf

Cerezuela, L. (2012). Principios internacionales de la arqueología virtual. Recuperado de http://e-portfolioseav.blogspot.pe/2012/11/principios-internacionales-de-la.html

CNN. (2005). Inventan un láser para preservar los monumentos históricos de la humanidad. Recuperado de http://cnnespanol.cnn.com/2015/06/24/inventan-un-laser-para-preservar-los-monumentos-historicos-de-la-humanidad/\#0

Combes, L. (2001). El poder de transformación de los medios digitales. En V Congreso Iberoamericano de Gráfica Digital. Congreso llevado a cabo en la Universidad del Bío-Bío. Concepción, Chile.

Datos para la crónica del Internet en el Perú: 20 años de Internet. (17 de Mayo de 2011). Recuperado de http://blog.rpp.com.pe/lexdigital/2011/05/17/datos-para-la-cronica-del-internet-en-elperu-20-anos-de-internet/

Dueñas, M. (2014). Registro arqueológico en 3D mediante fotogrametría de rango corto (Tesis de Licenciatura). Facultad de Ciencias Sociales y Humanidades. Universidad Autónoma de San Luis de Potosí, Bolivia.

Gómez, L. \& Quirosa, V. (2009). Nuevas tecnologías para difundir el patrimonio cultural: las reconstrucciones virtuales en España. Revista Electrónica de Patrimonio Histórico E-rph, 1-23. Recuperado de http://archaeology.huji.ac.il/depart/computerized/papers/jas2008_g.pdf 
devenir VOL. 3, N5, ENERO - JUNIO 2016, PP. 113-132 - ESTUDIOS | ISSN 2312-7570

UNIVERSIDAD NACIONAL DE INGENIERÍ, LIMA

Hayakawa, J. (2010). Gestión del patrimonio cultural y centros históricos latinoamericanos. Lima, Perú: Universidad Nacional de Ingeniería.

Karasik, A \& Uzy, S. (2008). 3D scanning technology as a standard archaeological tool for pottery analysis: practice and theory. Journal of Archaeological Science, 35(2008), 1148-1168

Organismo Superior de Inversión Privada en Telecomunicaciones. (2002). Diagnóstico de la situación de Internet en el Perú. Recuperado de https://www.osiptel.gob.pe/Archivos/Sector_telecomunicaciones/Desarrollo_Sector/Hito_InternetPer\%C3\%BA.pdf

Parry, R. (2007). Re-coding the museum: digital heritage and the technologies of change. Londres, Reino Unido: Routledge.

Pereira, J. (2013). Modelado 3D en patrimonio cultural por técnicas de structure from motion. Recuperado de http://www.iaph.es/phinvestigacion/index.php/phinvestigacion/article/ view/12/33\#.WHA8KPI95PY

Pierrot-Deseilligny, M., De Luca, L. \& Remondino, F. (2011). Procedimientos automatizados basados en imagen de artefactos precisos. Modelado en 3D y Ortoimagen. En XXIIIth Internacional CIPA Simposio. Simposio llevado a cabo en Praga, República Checa.

Piquer, C. (2005). Nuevas tecnologías y patrimonio desaparecido (Colección Biblioteca TC. Investigando los bienes arquitectónicos). Valencia, España: Departamento de Expresión Gráfica Arquitectónica de la Universidad Politécnica de Valencia.

Realidad virtual. (2014). En Diccionario de la Real Academia Española. (23 edición). Recuperado de http://dle.rae.es/?id=VH7cofQ

Ristevski, J. (marzo de 2006). Professional Surveyor Magazine. Recuperado de http://archives.profsurv.com/magazine/article.aspx?i=1555

Rivera, J. (2003). Nuevas tendencias en la identificación y conservación del patrimonio. Valladolid, España: Junta de Castilla y León, Universidad de Valladolid.

Zvietcovich, J. (2014). 3D updating of solid models based on local geometrical meshes applied to the reconstruction of ancient monumental structures (Tesis de maestría). Pontificia Universidad Católica del Perú. Lima, Perú. 